\title{
Proportion of Osteoporotic Women Remaining at Risk for Fracture Despite Adherence to Oral Bisphosphonates
}

\author{
Erik A. Imel ${ }^{1,2}$, George Eckert ${ }^{3}$, Ankita Modi ${ }^{4}$, Zhuokai $\mathrm{Li}^{3}$, Joel Martin ${ }^{2}$, Anne de \\ Papp $^{4}$, Katie Allen ${ }^{2}$, C. Conrad Johnston ${ }^{1}$, Siu L. Hui ${ }^{2,3}$, Ziyue Liu ${ }^{3}$ \\ ${ }^{1}$ Indiana University School of Medicine, ${ }^{2}$ Regenstrief Institute, \\ ${ }^{3}$ Indiana University School of Public Health \\ ${ }^{4}$ Merck, Sharp and Dohme, Inc.,
}

\section{Corresponding author:}

Erik A. Imel

eimel@iu.edu

Division of Endocrinology and Metabolism

Department of Internal Medicine

Indiana University School of Medicine

1120 W. Michigan Street

Gatch Clinical Building 459

Indianapolis, Indiana 46202-5111

Telephone: 317-274-1339

Fax: 317-278-0658

\section{Acknowledgements:}

Funding Source: This research was funded by a grant under the Merck- Regenstrief Program in Personalized Health Care Research and Innovation, a collaboration between Merck, Sharp \& Dohme and the Regenstrief Institute.

Conflict of Interest Disclosures: Erik A. Imel has received research funding from Merck, Sharpe \& Dohme. Ankita Modi and Anne de Papp are employed by Merck, Sharpe \& Dohme. All other investigators declare that they have no conflict of interest.

This is the author's manuscript of the article published in final edited form as: 


\section{Abstract:}

Background: Adherence to oral bisphosphonates is often low, but even adherent patients may remain at elevated fracture risk. The goal of this study was to estimate the proportion of bisphosphonate-adherent women remaining at high risk of fracture.

Methods: A retrospective cohort of women aged 50 years and older, adherent to oral bisphosphonates for at least two years was identified, and data were extracted from a multi-system health information exchange. Adherence was defined as having a dispensed medication possession ratio $\geq 0.8$. The primary outcome was clinical occurrence of: low trauma fracture (months 7-36), persistent T-score $\leq-2.5$ (months 1336 ), decrease in bone mineral density (BMD) at any skeletal site $\geq 5 \%$, or the composite of any one of these outcomes.

Results: Of 7435 adherent women, 3110 had either pre- or post-adherent DXA data. In the full cohort, $7 \%$ had an incident osteoporotic fracture. In 601 women having both preand post-adherent DXA to evaluate BMD change, $6 \%$ had fractures, $22 \%$ had a posttreatment T-score $\leq-2.5$, and $16 \%$ had BMD decrease by $\geq 5 \%$. The composite outcomes occurred in $35 \%$. Incident fracture was predicted by age, previous fracture, and a variety of co-morbidities, but not by race, glucocorticoid treatment or type of bisphosphonate.

Conclusion: Despite bisphosphonate adherence, $7 \%$ had incident osteoporotic fractures and $35 \%$ had either fracture, decreases in BMD, or persistent osteoporotic BMD, representing a substantial proportion of treated patients in clinical practices remaining at risk for future fractures. Further studies are required to determine the best achievable goals for osteoporosis therapy, and which patients would benefit from alternate therapies. 


\section{Highlights:}

- In women adherent to oral bisphosphonates $7 \%$ had incident osteoporotic fracture.

- In those with DXA pre and post adherence, $22 \%$ had persistent osteoporotic Tscores.

- In those with DXA pre and post adherence, $16 \%$ had BMD declines $\geq 5 \%$ at any site.

- A third of patients had one or more of these outcomes despite adherence to oral bisphosphonates. 


\section{Background:}

Osteoporosis is a condition of low bone density leading to fracture. Each year over 1.3 million fractures occur in the United States, the majority of which are due to age-related osteoporosis [1]. In 2010, 54 million adults age 50 and older in the United States were estimated to have osteoporosis or osteopenia as defined by BMD measurement [2]. Though the age-specific rates of hip fractures have been reported to be decreasing in some, albeit not all, countries [3, 4], osteoporosis remains a major public health problem that will continue to increase in prevalence as the population ages.

Despite the availability of highly efficacious treatments for osteoporosis such as oral bisphosphonates, low treatment initiation rates [5] and low adherence among patients in clinical settings [6] limits the benefits. In clinical trials, osteoporosis agents decrease hip fractures by up to $50 \%$, vertebral fractures by $30-70 \%$ (depending on whether detected based on clinical symptoms or morphometry), and nonvertebral fractures by up to $30 \%$ $[7,8]$. When patients are adherent and persistent in their treatments, the reduction in fracture rates has been reported to be similar between clinical trials and observational cohorts [9]. However, no osteoporosis treatment eliminates fractures and some patients that are adherent and persistent in their osteoporosis treatments may remain at elevated risk for future fractures.

A group of clinician/researchers have suggested a goal-directed strategy to initiate or change osteoporosis treatments based on targets to achieve a certain BMD value or level of fracture risk [10]. Concerns regarding difficulties in setting achievable goals have been raised [11], and these difficulties were later demonstrated empirically by showing that the FRAX Score was not responsive enough to treatment to be reliably used as target [12].

A working group for the International Osteoporosis Foundation (IOF) proposed a set of criteria for defining inadequate clinical treatment response (which may or may not be due to low adherence) that included the occurrence during osteoporosis treatment, of two or more incident fragility fractures, a significant decrease in bone mineral density 
(BMD), (i.e. beyond the LSC of the measurement method), or change in bone turnover markers in the opposite direction of that induced by the treatment agent's mechanism [8]. It was suggested that although these patients may have had some benefit from their osteoporosis drug regimen, that the occurrence of any of these criteria may indicate a need to consider altering treatment in such patients to optimize risk reduction. The occurrence of one or more fractures is a risk factor for additional future fractures in both untreated patients [13], and in those treated with bisphosphonates [14]. Furthermore persistence of osteoporotic T-scores or further decrease in BMD after treatment indicates a higher risk of subsequent fracture compared to those with higher post treatment T-scores, and potential to benefit from additional treatment [15]. Thus the outcomes of fracture, or the surrogate outcomes of decline in BMD or persistent low $\mathrm{BMD}$, are often used by practitioners to guide decisions regarding continuing or switching therapies, because the occurrence of each of these is associated with an elevated risk of fracture relative to other treated patients [16, 17].

The various criteria proposed for inadequate response can be adapted and applied to electronic medical records to identify patients remaining at high risk for fractures despite treatment. Based on readily available data in the clinical records, patients on treatment can be assessed for whether 1) they incur one or more fractures while adherent to treatment, 2) their BMD remains low, or 3) their BMD decreases significantly while adherent to treatment. The primary objective of this analysis was to estimate the proportion of osteoporotic women in a large clinical medical records system who, despite having been adherent to oral bisphosphonate therapy, remain at high risk of fracture, as indicated by the occurrence of one of these three outcomes. We also identified clinical and demographic factors associated with remaining at high risk.

\section{Methods}

\subsection{Overview and Study Design}

This is a retrospective cohort study of women aged 50 years and older, who have been adherent to oral bisphosphonates for at least two years. The cohort was 
identified and all study data were extracted from a health information exchange as described below.

\subsection{Data Source and Definitions}

The study cohort and data were extracted from the Indiana Network for Patient Care (INPC), a leading operational regional Health Information Exchange formed in 1994 by the Regenstrief Institute and the five major hospital systems in Indianapolis, later joined by dozens more institutions around the state. Data types available from different institutions include diagnoses (ICD-9 codes), procedures (CPT codes), pharmacy transactions, orders, imaging studies, and laboratory results, though data completeness varies across INPC institutions. The study was approved by the Institutional Review Board of Indiana University. The study subjects were restricted to only those patients who had been adherent to at least one oral bisphosphonate for two years (see inclusion criteria below). Data from all hospitalizations including emergency room visits within the participating health systems are included in this dataset. In 2004 a program was initiated to send data from all emergency room visits in the state of Indiana to the INPC (including emergency room visits at hospitals that do not send other data), which would increase the capture of fractures.

Dual-energy $\mathrm{x}$-ray absorptiometry (DXA) measurements of bone mineral density (BMD) and their associated T-scores at the spine, femoral neck, and total hip were available in a subset of patients whose health systems submitted such data to the INPC. The BMD data included a combination of direct uploads from four DXA machines (11\% of the total BMD data in this analysis) and data parsed from text reports $(89 \%)$. The data directly uploaded from DXA machines (which included three machines used for medical research) incorporated both T-score and the BMD values in $\mathrm{g} / \mathrm{cm}^{2}$. For quality control of data obtained from text reports, the $\mathrm{T}$-scores were plotted against the BMD values in $\mathrm{g} / \mathrm{cm}^{2}$, and compared to the equations for BMD measurement locations (total hip, femur neck, lumbar spine) according to different DXA machine manufacturers. Deviations from these equations triggered manual reviews of the reports and obvious typographical errors were corrected. 
When the deviation could not be reconciled, the data were excluded. For the analysis of the complete-outcomes subcohort (having both pre and post index DXA), only reports listing BMD measures in $\mathrm{g} / \mathrm{cm}^{2}$ listed were included.

Clinical osteoporotic fractures were identified by ICD-9 codes (Supplemental Table 1). Fractures at the following sites not typically associated with osteoporosis were excluded: skull, craniofacial, phalangeal, carpal, metacarpal, tarsal, and metatarsal fractures. Fractures were excluded as outcome events if records indicated concurrent fractures at 5 or more different skeletal sites (coded within a 30 day window), suggesting a high trauma event. The arbitrary cutoff of 5 fractures was based on a limited chart review of occurrence of co-incident fracture codes and an estimate of the likely range in number of possible fractures occurring with low trauma vs high trauma events. However, in analysis no subject in our study had more than 3 concurrent fractures. Comorbidities were extracted from ICD-9 codes and medications were extracted from dispensing records.

\subsection{Inclusion/exclusion Criteria}

The study time period spanned 2000-2012, when bisphosphonates were widely used. Only women aged 50 years and over were included if they satisfied the criterion for adherence to at least one oral bisphosphonate over at least two years, regardless of whether they had any indications for treatment. Adherence was defined as "proportion of days covered" (PDC) [18] of at least 0.8 over 2 years, with no gap greater than 30 days between covered days. Only the first documentable continuous adherent period of at least 2 years for each subject was included in the study. The date at the beginning of the adherent period was considered the index date, and the woman's age at the index date was her index age. Excluded were patients with osteogenesis imperfecta, hypercalcemia or Paget's disease ICD9 codes. Patients that had a record of intravenous bisphosphonate treatments or denosumab from 2 years prior to the index date through the adherent period were excluded. Other pre-index osteoporosis treatments, including oral bisphosphonates that did not meet the criteria for adherence prior to the index date, and calcitonin or 
teriparatide, were treated as covariates in modeling outcomes. Concurrent medications during the adherent period (which sometimes included calcitonin, estrogens or selective estrogen receptor modifiers, as well as medications for comorbidities) were also treated as covariates. However, the use of teriparatide, intravenous bisphosphonates and denosumab were exclusionary if occurring during the adherent period.

\subsection{Study outcomes}

\subsubsection{Outcome definitions}

Outcomes for patients who had been adherent to oral bisphosphonates for at least 2 years (and may or may not be adherent in the third year) were measured through month 36 from the index date because the effects of bisphosphonates last beyond the treatment period [19]. Patients were considered to remain at high risk of fracture if they satisfied at least one of the following three criteria:

1) Low post-treatment T-score - defined as a T-score of $\leq-2.5$ at any of the following skeletal sites (spine, femur neck or total hip) during months 13-36 from the index date.

2) Significant decline in BMD - defined as a decrease of $\geq 5 \%$ (at any of the measured sites: spine, femur neck or total hip) these measured skeletal site from the pre-treatment BMD (latest value within 2 years prior to the index date) to any post-treatment value during months 13-36 from the index date.

3) Any clinically coded non-traumatic osteoporotic fracture (as defined above; codes listed in supplemental Table 1) occurring in months 7-36 from the index date.

Osteoporotic fractures were counted as events beginning after completing month 6 because fracture rates in treated and untreated patients begin to diverge between treatment and placebo arms in the first 6-12 months in randomized trials of oral bisphosphonates [20, 21]. In contrast, to allow adequate time for BMD response to oral bisphosphonates, post-index BMD measurements were counted only from the 
beginning of month 13 onwards (i.e. from 13-36 months). While the fracture outcome could be ascertained on the entire cohort, the outcome of low posttreatment T-score could be ascertained only on the subset of subjects with BMD measurements in months $13-36$ from the index date. The choice of -2.5 as a cutoff for the post-treatment T-score is based on the patient still meeting the definition of osteoporosis. The IOF recommends a decrease of $4-5 \%$ in BMD be generally considered a significant decline, depending on the precision of the individual machine [8]. Since the INPC data were received from multiple institutions with variable levels of quality control in their DXA measurements and the precision level for most contributing machines is not provided to INPC, the higher $5 \%$ value was chosen to indicate a significant decline. A composite outcome of "remaining at risk of fracture" was defined as a positive outcome in any one of the 3 individual outcomes. This could be ascertained only in the complete-outcomes subcohort.

\subsubsection{The complete-outcomes subcohort}

Within this subset, the outcome of a significant drop in BMD could be ascertained only in those subjects who also had at least one BMD measurement at the corresponding skeletal site(s) during the two years prior to the index date. This smallest subset of 601 subjects, having both pre- and post-treatment BMD during the defined periods, comprised the "complete-outcomes subcohort".

\section{$\underline{2.5 \text { Covariates }}$}

Patient demographics included age and race. Clinical characteristics included fractures and osteoporosis drug treatments prior to the index date, type of bisphosphonate and other co-medications used during the adherent period, and chronic comorbidities. Comorbidities were captured by ICD-9 codes. The Charlson Comorbidity Index was calculated, using a modified version excluding age as a factor [22]. The Charlson Comorbidity Index is generated from ICD9 codes to categorize burden of comorbidities. A higher score on the Charlson Comorbidity index indicates greater number or degree of comorbidities and is a predictor for mortality or for complications in a variety of disease states [22, 23]. In addition 
codes for other major disease groups and selected conditions that may affect bone metabolism or risk of falls were also collected.

\subsection{Statistical Analyses}

Descriptive statistics were calculated for the entire cohort, and in the completeoutcomes subcohort (having both pre and post index DXA). Subject characteristics and fracture outcomes of the subcohort were compared to subjects not in the subcohort to identify how the subcohort might differ systematically from the remainder of the overall cohort. A p-value of $<0.05$ was considered statistically significant.

Logistic regression modeling was used to identify factors that predict outcomes. Predictors included demographic and clinical characteristics of the subjects. Preliminary analyses used only one predictor in each model to examine apparent associations. Then stepwise model selection was used to fit multivariable models. Predictors in the stepwise multivariable model were not pre-selected; however, preindex T-score was excluded from the analysis because of strong relationship with post-treatment T-scores. For inclusion of a variable, $p$-values of 0.05 or less were required for inclusion versus elimination from the model at each step. A model was fitted to predict fractures since this outcome was available on the entire cohort, and the results could be compared to other studies. The model for predicting the composite outcome was then fitted to the complete-outcomes subcohort. Sensitivity analyses were also performed by using a 3\% drop in BMD rather than $5 \%$ for the definition of a significant drop. Comparison between BMD change category and fracture occurrence was conducted using Mantel-Haenszel chi-square test (using the ordinal BMD change categories).

\section{Results}

The study cohort was selected from an initial set of 8,339 women who had been adherent to oral bisphosphonate treatments for at least 2 years. Figure 1 shows the application of the various exclusion criteria resulting in the final analysis cohort of 
7435 women. Only 3110 in this cohort had any DXA data in the two-year pre-index period and/or months 13-36 post-index. In a small subset of reports, only T-scores were reported without the absolute BMD values $(0.07 \%$ of reports at the total hip, $6.9 \%$ at the femur neck, $0.1 \%$ at the spine). Of the 620 subjects who had DXA measurements in both the requisite pre- and post-treatment periods, only 601 had BMD values at the same skeletal site (and measured in $\mathrm{g} / \mathrm{cm}^{2}$ ) in both periods so that percent change in BMD could be calculated, and these subjects comprised the "complete-outcomes subcohort."

Table 1 shows the characteristics of subjects in the overall cohort, and in the completeoutcomes subcohort (having at least one pair of DXA measurements in the eligible preand post-treatment periods at the same skeletal site). Patients in the completeoutcomes subcohort were younger $(p<0.01)$, and were more likely to be white $(p<0.0001)$ compared to the rest of the cohort. Since the vast majority of patients in INPC are white (most likely including those with missing race), subsequent analyses used black and non-black categories, with proportions similar between the completeoutcomes subcohort and the entire cohort. Subjects in the complete-outcomes subcohort had a longer adherent period $(p<0.001)$, and were less likely to have diabetes $(p<0.05)$. During the pre-index period, subjects in the complete outcomes subcohort were also more likely to have received any previous osteoporosis treatment $(p<0.01)$, any previous bisphosphonate $(p<0.05)$, or alendronate $(p<0.001)$, than those in the full cohort.

Table 2 shows the different oral bisphosphonates dispensed during the adherent periods. In each cohort, a small subset received more than one oral bisphosphonate sequentially during the study period. Subjects in the complete-outcomes subcohort were more likely to have taken alendronate $(p<0.01)$ and less likely to have taken risedronate during the adherent period $(p<0.01)$. Other co-medications taken in the same period are also presented; only estrogens were taken by a smaller proportion of subjects in the complete-outcomes subcohort $(p<0.05)$. 
Table 3 summarizes the study outcomes in the post-index period. Of the entire cohort of 7435 women, $499(7 \%)$ had at least one coded clinical fracture event and $174(2 \%)$ had 2 or more distinct fracture events between $7 \& 36$ months post-index. In our cohort most fracture events involved single fractures. Between the index date and 3 years after index there were 506 individual fracture events in patients with only 1 fracture at a time, 76 with 2 co-incident fractures, 13 with 3 co-incident fractures, and none with 4 or more co-incident fractures. However, only fractures occurring from months 7-36 were counted as outcomes in the analysis. From 7-12 months after index, 122 fracture events occurred; from 13-24 months, 288 fracture events occurred; and from 25-36 months, 367 fracture events occurred. The osteoporotic fracture rate was similar in the complete-outcomes subcohort (6\%) to the entire cohort $(7 \%)$.

A low post-treatment T-score $\leq-2.5$ occurred in $20 \%$ of the full cohort having available DXA data, and in $22 \%$ of the complete-outcomes subcohort (having preand post-treatment DXA). Decline in BMD could only be assessed in the completeoutcomes subcohort. Pre-index, 152 women started with T-scores $\leq-2.5$, of which $55(36 \%)$ had post adherent T-scores >-2.5. Of the remaining 449 women starting with pre-index T-scores >-2.5, 34 (8\%) ended with post-adherent T-scores $\leq-2.5$. Out of the 131 women who ended with T-scores $\leq-2.5,97(74 \%)$ of them had started with pre-index T-scores $\leq-2.5$. The percent of subjects having BMD increases or decreases $\geq 5 \%$, or with BMD remaining within $< \pm 5 \%$ are listed in Table 3 . Not every patient had data available for all 3 sites. In this subcohort, more patients had increases of BMD at the spine (37\%), while more patients had decreased BMD at the femur neck (16\%). When assessed for the worst BMD change at any measured site, $16 \%$ of adherent women had a decline in $\mathrm{BMD} \geq 5 \%$ during treatment at one or more sites.

The composite outcome of having at least one of the three outcomes is only assessable in the complete-outcomes subcohort having both pre- and post-adherent DXA. In this subgroup we identified $207 / 601$ (35\%) with positive composite 
outcomes: of these 207 women, $64 \%$ had a T-score $\leq-2.5 ; 47 \%$ had a significant decline in $\mathrm{BMD} \geq 5 \%$; and $18 \%$ had a clinical fracture.

Table 4 shows the univariate estimates of association between the risk of a fracture outcome and each covariate, except for the use of thiazides, proton pump inhibitors, SSRIs/SNRIs, anticonvulsants, statin, antidiabetics, anticoagulants, and cyclosporins, which were not associated with any outcome in any analyses. The significant predictors of fracture include the well-known risk factors of age, previous fracture and low T-scores, as well as a number of chronic diseases. Black (versus non-black) race was not a predictor of fracture. The types of oral bisphosphonates were not associated with fracture outcomes, but the use of calcitonin before or concurrently with bisphosphonate treatment had an association with higher fracture risk, possibly due to providers treating those deemed at higher risk with dual therapy. Similarly those with previous treatment with teriparatide were also at higher risk of fracture during subsequent bisphosphonate adherence, likely identifying potent anabolic therapy being used in those at highest baseline risk. Higher Charlson Comorbidity Index and multiple individual comorbid conditions including AIDS, malignancy, chronic pulmonary diseases, chronic joint conditions, neurologic, cardiovascular, gastrointestinal and renal conditions and diabetes were all associated with increased risk of fracture despite bisphosphonates. Concomitant glucocorticoids were not predictive of fracture while adherent to bisphosphonates. Other co-medications during the adherent period did not predict fracture outcomes, though there was a nonsignificant trend for increased risk of fracture with use of tamoxifen.

When the univariate analyses in Table 4 were applied to the complete-outcomes analysis subcohort for associations with the composite outcome, the associations with individual predictors remained similar for the known osteoporosis factors of age, previous fracture and low T-scores, but weakened for most chronic conditions (as measured by odds ratio). However the associations with pre- and post-index use of calcitonin remained and had more extreme odds ratios, even though the $p$-values were larger due to the smaller sample size. 
After all potential predictors (regardless of significance in univariate analyses) were entered stepwise into a multiple logistic model, age and previous fracture remained predictive of fractures in the study period, as did the modified Charlson Comorbidity Index and several individual chronic conditions. Pre-index (nonadherent) use of alendronate was associated with a lower fracture risk during subsequent oral bisphosphonate adherence, while pre-index use of calcitonin was associated with a higher subsequent fracture risk (see Table 5). Black race and pre-index T-score category $(>-1,-1$ to $-2.5,<-2.5)$ did not predict fractures in multiple logistic regression. The OR for the composite outcome was increased by age, race (nonblack), hyperparathyroidism, and use of estrogens.

As a secondary analysis, predictors of decline in BMD $\geq 5 \%$ were analyzed in the complete-outcomes subcohort, having pre and post adherent DXA. In univariate analysis of association the type of oral bisphosphonates was not a significant predictor of BMD decline. Each oral bisphosphonate was individually compared to the other two. BMD decreased $\geq 5 \%$ in $21 \%$ of patients treated with risedronate versus $15 \%$ of patients with other oral bisphosphonates $(p=0.08)$; in $17 \%$ of patients treated with ibandronate versus $16 \%$ of patients with other oral bisphosphonates $(p=0.93)$; and in $16 \%$ of patients treated with alendronate versus $18 \%$ of patients with other oral bisphosphonates $(p=0.60)$. Variables increasing odds ratio for BMD decrease in stepwise multivariable analysis included age $(p=0.0377$, odds ratio 1.03 $(1.00,1.05))$, chronic pulmonary diseases $(p=0.0270$, odds ratio $1.74(1.07,2.85))$, and estrogen use $(p=0.0183$, odds ratio $2.39(1.16,4.93))$. The type of bisphosphonate was not significant in stepwise multivariable models.

In the complete-outcomes subcohort, the occurrence of one or more fractures from month 7-36 was not related to different levels of change in BMD (Mantel-Haenszel chi square test $p=0.56)$. Of 98 patients in whom BMD decreased by $\geq 5 \%, 8(8 \%)$ sustained fracture. Of 434 patients without change in BMD (BMD within $\pm<5 \%$ ), 22 $(5 \%)$ of patients sustained fracture. In 69 patients BMD increased by $\geq 5 \%$, and 8 $(12 \%)$ had fracture. Similarly when BMD was treated as a continuous variable, there was no relationship with clinical fracture incidence $(p=0.73)$. 
When limiting to 2 or more clinical fractures as an outcome, for the multivariable analysis the significant variables and the odds ratios were similar and fairly stable (Supplemental Table 2) compared to those using 1 or more fractures as an outcome (Table 3). This was true for fractures as the endpoint, and also for the composite outcome. However in this analysis, risedronate use (compared to other bisphosphonates) was associated with the composite outcome including 2 or more fractures, while it was not associated with a composite outcome including 1 or more fractures.

\section{Discussion}

In a population of patients from a health information exchange network, we estimated that patients who have been adherent to oral bisphosphonates for at least two years have an absolute clinical fracture risk of $7 \%$ (including both vertebral and non-vertebral fractures) during months 13-36 from the beginning of the adherent period. These patients can be interpreted as remaining at high risk of fractures in part because past fractures predict future fractures. In the subset of patients with sufficient bone density measurements to determine declines in bone density, we estimated that $35 \%$ remained at risk for osteoporotic fractures based on the occurrence of either: one or more fractures while adherent to bisphosphonates, a Tscore remaining in the osteoporotic range, or a significant decrease in BMD during two to three years of treatment.

The International Osteoporosis Foundation Inadequate Responders Working Group [7] proposed pragmatic criteria suggesting inadequate response to osteoporosis treatment including occurrence of two or more fractures, or a decrease in BMD, or change in bone turnover markers inconsistent with the specific drug mechanism of action. Unfortunately, this clinical patient care database did not have bone turnover marker data for analysis in this adherent population. Some authors have suggested that a persistent osteoporotic T-score indicates patients at higher fracture risk, who might not be candidates for drug holidays [23]. Similarly some authors have proposed considering a BMD target (such as achieving a non-osteoporotic T-score) 
as a hypothetical goal of treatment [9], based on the finding that persistent BMD Tscores less than -2.5 after treatment with alendronate indicated a higher risk of subsequent fracture in the FLEX trial [14]. The occurrence of any fracture is still a risk factor for future fractures in both untreated patients [12], and in bisphosphonate treated subjects [13]. In a FIT trial analysis, out of 1841 patients receiving alendronate 248 (13.5\%) sustained a first symptomatic fracture. Out of that subgroup of 248 subjects with first fracture, 51 (or 20.6\%) sustained a second symptomatic fracture on treatment. Thus, even on oral bisphosphonates, the occurrence of one fracture indicated higher risk of subsequent fracture (compared to risk of first fracture on treatment) [13]. Of note the risk of a second fracture while on alendronate in that trial was still less than the risk of second fracture in the placebo group. We sought to apply a combination of these proposed factors as indicating a potential increased fracture risk, by collectively assessing the occurrence of one or more fractures while adherent to bisphosphonates, a T-score remaining in the osteoporotic range, or a significant decrease in BMD at either the hip or the spine.

The advantage of using health information exchange data is that it reflects real-life practice and patient behavior from a wide range of types of practices and patient backgrounds. Strengths of this study include its assessment of the effectiveness of actual treatment practices in our population, and the inclusion of clinical DXA and documented coded fractures as outcomes. However, there are limitations to using an administrative database to make inferences regarding the outcomes of clinical treatment modalities, and for determining which patients might require a change in therapy.

One limitation regarding outcome measurement includes that actual clinical practice may not result in the timing of sequential bone density measurements being on either side of clear time periods of treatment adherence and at appropriate intervals to assess the BMD outcomes in all subjects. The bone density related outcomes were limited to those patients whose BMD studies were performed at appropriate time intervals in relation to the actual adherent period. Thus not all subjects had both pre and post adherent period DXA scans. In clinical practice significant time intervals may occur between a diagnostic DXA scan, and the initiation of therapy, 
while the actual adherence periods to therapy may be variable within an individual patient. In addition clinical DXA scans may not be timed around an adherent period, but may be planned based on payor coverage, or other factors. Likewise in clinical practice some patients may have had initial or post-treatment DXA scans at facilities that were outside the INPC networks. Another limitation of our study is that clinical DXA measurements are likely to have lower precision than DXA performed on research units, and for this study the least significant change information was not accessible. While we expect the T-score to be reasonably reliably measured in clinical practice, the measure of BMD change likely does not attain the precision expected from research trials. It is possible that the least significant change is higher than $5 \%$ in clinical practice facilities where some technicians may not be rigorously trained. However, it is important that we used the same information that the patient's treating clinician would have received, and which would impact clinical decision making. Thus the results seen in this study likely represent the situation faced by many treating clinicians.

Our study could only detect fractures that were clinically recognized and coded. Thus asymptomatic morphometric vertebral fractures are less likely to be included. Furthermore, some fractures will be missed if not evaluated or treated within the participating health systems. If such fractures occurred, our results would be an underestimate of the true fracture incidence in patients adhering to oral bisphosphonates. However, because of the robust statewide emergency room data and extensive hospitalization data, most clinical fractures occurring in the state are likely to be captured.

This study result may underestimate the risk of these outcomes in osteoporotic patients treated with bisphosphonates, as this was a subset of adherent patients [6]. Because patients may not become immediately adherent at the start of an initial prescription, patients were allowed to have oral bisphosphonates dispensed prior to the start of the recorded adherent period. Of note, this 'sub-adherent' treatment would still likely have some effect on bone turnover, thus inclusion of these subjects would tend to decrease the estimate of subjects having one or more of the outcome 
events. Interestingly, those patients with 'sub-adherent' alendronate treatment prior to the adherent period did have lower fracture risk in multivariable analysis [OR 0.69 $(95 \% \mathrm{Cl} 0.54,0.89)]$, likely due to the cumulative effects of treatment with bisphosphonates even though initially used in a sub-adherent manner.

Compliance was assessed based on drug dispensing days covered, with the assumption that the medication once obtained was actually taken properly and reliably by the patient. However, neither appropriate provider instructions, nor correct administration by the patient (i.e. without food, etc.), can be assured in this study. Additionally, a comparator group of non-treated or non-adherent patients was not analyzed, in part because while dispensing of medications could be confirmed, lack of treatment is more difficult to ascertain with certainty, as patients may receive prescriptions at non-participating pharmacies. Of note, previous studies have suggested that bisphosphonate treatment as assessed in clinical databases indicates similar relative fracture risk reduction as in trials, which correlated to adherence rates [24, 25]. However prospective trials following adherent oral bisphosphonate treated subjects in clinical practices would better define the occurrences of these outcomes.

Our data cannot specifically guide treatment choices in subjects having one of these events, as we could not evaluate the effect of treatment changes in the subgroup having incident fractures, decreasing BMD or persistent osteoporotic T-scores. There are some published data from clinical trials of switching subjects from oral bisphosphonate to other agents (nicely reviewed by Eiken and Vestergaard [26]). Studies in prior bisphosphonate users have indicated BMD increases at the spine or total hip after switching to denosumab or teriparatide, although a transient decrease in areal BMD at the total hip occurred during the first 6 months of teriparatide. Switching from alendronate to zoledronate or raloxifene did not increase BMD further. However, the trials of treatment switching generally did not limit enrollment to subjects having fractures or one of the BMD outcomes listed in our trial, but rather included subjects on an oral bisphosphonate regardless of previous treatment response. Thus it is not certain whether patients with incident fractures, decreasing BMD or persistent low T-scores while adherent to oral bisphosphonates would 
actually benefit from a switch to other osteoporosis agents. Prospective trials with these specific enrollment criteria would be needed to address this issue.

Since our study only included subjects during a period of time with adherence to oral bisphosphonates, the findings are not generalizable to subjects receiving intravenous bisphosphonates. Patients sustaining fractures on treatment may have been switched to intravenous bisphosphonates, in which case their potential eligible time in the study period would have ended, and they would not have been included in our study if the oral bisphosphonate treatment was for less than 2 years. Thus higher risk subjects might have been excluded from the study, which would likely lead to an underestimate of the incidence of fracture or the BMD outcomes. Furthermore patients with contraindication to oral bisphosphonate would be excluded from this study regardless of whether they had higher or lower risk of fracture compared to the studied population. Higher risk patients on oral bisphosphonates who may have refused other therapies also could have biased the results in favor of higher incidence of outcomes.

This study represents a cross-section of individual risk. Patients at higher baseline risk of fracture benefit the most from therapy targeted at reducing fracture risk, but also are most likely to remain at high fracture risk even after potent therapy, limiting attempts to treat to a specific desired target of BMD or fracture risk level $[11,12]$. Interestingly pre-index treatment with calcitonin or teriparatide before the adherent bisphosphonate period, and co-treatment with calcitonin and bisphosphonates, were both associated with increased fracture risk during months 13-36. This may be explainable by a greater likelihood for providers to treat higher risk patients with teriparatide, or to attempt combination therapy in those at higher risk. However in univariate analysis, concomitant raloxifene did not influence risk of fractures or composite outcomes in bisphosphonate adherent subjects. Co-medication with raloxifene and bisphosphonates may occur due to the common practice of prescribing raloxifene for potential extra-skeletal benefits. In short term clinical trials, raloxifene and alendronate in combination have been shown to increase BMD 
greater than either agent alone [27], although a fracture risk benefit from this combination therapy has not been demonstrated.

According to the findings of Hochberg et al, both absolute BMD and the magnitude of change on treatment had additive effect on the risk of fractures in bisphosphonate treated subjects in clinical trials[16]. A significant decline in BMD was observed in $16 \%$ of our subcohort having pre- and post-treatment DXA, which was considerably higher than in clinical trials[16, 17]. However the fracture rates were comparable between our study and clinical trials of oral bisphosphonates. In fact, in our study, change in BMD did not predict the occurrence of clinical fractures, whether BMD change was evaluated as a continuous variable or as categories of change. The incidence of clinical fracture was similar whether there was an increase or decrease in $B M D$. This would suggest that measurements of BMD change in the context of clinical practice may be a poor surrogate for clinical fracture risk prediction.

Sambrook showed that fractures could be predicted from relatively simple algorithms that performed as well as more complex ones. [28] Since older patients, non-black patients, and those with hyperparathyroidism or concomitant estrogen use tended to remain at higher risk of fracture despite being adherent to bisphosphonate treatment, these are the patients who may need to be considered early for alternative treatments or monitored more closely to decide whether they need alternative treatments. Exactly what those criteria would be beyond BMD or new fractures are uncertain, as algorithms such as FRAX are not responsive enough to therapy to reliably detect a change in risk with therapy [12].

In summary, despite adherence, a substantial proportion of patients in clinical practices treated with oral bisphosphonates remain at risk for fractures and a third of patients had one of the suboptimal clinical outcomes. Although clinical trials have indicated a decrease in fracture risk even with declines in BMD during bisphosphonate therapy, the benefit achieved by such patients is not likely to be optimal. Further studies are required to identify which patients require alternate therapies to maximize their fracture reduction 
benefit, and how best to identify appropriate and achievable targets for goal-directed osteoporosis therapy. 


\section{References}

1. Melton LJ, 3rd, Thamer M, Ray NF, Chan JK, Chesnut CH, 3rd, Einhorn TA, Johnston CC, Raisz LG, Silverman SL, Siris ES (1997) Fractures attributable to osteoporosis: report from the National Osteoporosis Foundation. J Bone Miner Res 12:16-23

2. Wright NC, Looker AC, Saag KG, Curtis JR, Delzell ES, Randall S, Dawson-Hughes B (2014) The Recent Prevalence of Osteoporosis and Low Bone Mass in the United States Based on Bone Mineral Density at the Femoral Neck or Lumbar Spine. Journal of Bone and Mineral Research 29:2520-2526

3. Cooper C, Cole ZA, Holroyd CR, Earl SC, Harvey NC, Dennison EM, Melton LJ, Cummings SR, Kanis JA, Epidemiology ICWGoF (2011) Secular trends in the incidence of hip and other osteoporotic fractures. Osteoporos Int 22:1277-1288

4. Leslie WD, Morin SN (2014) Osteoporosis epidemiology 2013: implications for diagnosis, risk assessment, and treatment. Current opinion in rheumatology 26:440-446

5. Liu Z, Weaver J, de Papp A, Li Z, Martin J, Allen K, Hui S, Imel EA (2015) Disparities in osteoporosis treatments. Osteoporos Int In Press:

6. Imaz I, Zegarra P, Gonzalez-Enriquez J, Rubio B, Alcazar R, Amate JM (2010) Poor bisphosphonate adherence for treatment of osteoporosis increases fracture risk: systematic review and meta-analysis. Osteoporos Int 21:1943-1951

7. Body JJ, Bergmann P, Boonen S, Boutsen Y, Devogelaer JP, Goemaere S, Kaufman JM, Rozenberg S, Reginster JY (2010) Evidence-based guidelines for the pharmacological treatment of postmenopausal osteoporosis: a consensus document by the Belgian Bone Club. Osteoporos Int 21:1657-1680

8. Diez-Perez A, Adachi J, Agnusdei D, et al. (2012) Treatment failure in osteoporosis. Osteoporosis International 23:2769-2774

9. Wilkes MM, Navickis RJ, Chan WW, Lewiecki EM (2010) Bisphosphonates and osteoporotic fractures: a cross-design synthesis of results among compliant/persistent postmenopausal women in clinical practice versus randomized controlled trials. Osteoporos Int 21:679-688

10. Cummings SR, Cosman F, Eastell R, Reid IR, Mehta M, Lewiecki EM (2013) Goaldirected treatment of osteoporosis. J Bone Miner Res 28:433-438

11. McCloskey E, Leslie WD (2013) Goal-directed therapy in osteoporosis. Journal of Bone and Mineral Research 28:439-441

12. Leslie WD, Majumdar SR, Lix LM, Morin SN, Johansson H, Odén A, McCloskey EV, Kanis JA (2014) Can Change in FRAX Score Be Used to "Treat to Target"? A Population-Based Cohort Study. Journal of Bone and Mineral Research 29:1074-1080

13. van Staa TP, Leufkens HG, Cooper C (2002) Does a fracture at one site predict later fractures at other sites? A British cohort study. Osteoporos Int 13:624-629

14. Levis S, Quandt SA, Thompson D, et al. (2002) Alendronate reduces the risk of multiple symptomatic fractures: results from the fracture intervention trial. Journal of the American Geriatrics Society 50:409-415

15. Schwartz AV, Bauer DC, Cummings SR, et al. (2010) Efficacy of continued alendronate for fractures in women with and without prevalent vertebral fracture: the FLEX trial. J Bone Miner Res 25:976-982

16. Hochberg MC, Ross PD, Black D, Cummings SR, Genant HK, Nevitt MC, BarrettConnor E, Musliner T, Thompson D (1999) Larger increases in bone mineral density during alendronate therapy are associated with a lower risk of new vertebral fractures in women with postmenopausal osteoporosis. Fracture Intervention Trial Research Group. Arthritis Rheum 42:1246-1254 
17. Chapurlat RD, Palermo L, Ramsay P, Cummings SR (2005) Risk of fracture among women who lose bone density during treatment with alendronate. The Fracture Intervention Trial. Osteoporos Int 16:842-848

18. Choudhry NK, Shrank WH, Levin RL, Lee JL, Jan SA, Brookhart MA, Solomon DH (2009) Measuring concurrent adherence to multiple related medications. The American journal of managed care 15:457-464

19. Black DM, Schwartz AV, Ensrud KE, et al. (2006) Effects of continuing or stopping alendronate after 5 years of treatment: the Fracture Intervention Trial Long-term Extension (FLEX): a randomized trial. JAMA 296:2927-2938

20. Black DM, Cummings SR, Karpf DB, et al. (1996) Randomised trial of effect of alendronate on risk of fracture in women with existing vertebral fractures. Fracture Intervention Trial Research Group. Lancet 348:1535-1541

21. Harris ST, Watts NB, Genant HK, et al. (1999) Effects of risedronate treatment on vertebral and nonvertebral fractures in women with postmenopausal osteoporosis: a randomized controlled trial. Vertebral Efficacy With Risedronate Therapy (VERT) Study Group. JAMA 282:1344-1352

22. Deyo RA, Cherkin DC, Ciol MA (1992) Adapting a clinical comorbidity index for use with ICD-9-CM administrative databases. Journal of clinical epidemiology 45:613-619

23. Rattanasompattikul M, Feroze U, Molnar MZ, Dukkipati R, Kovesdy CP, Nissenson AR, Norris KC, Kopple JD, Kalantar-Zadeh K (2012) Charlson comorbidity score is a strong predictor of mortality in hemodialysis patients. Int Urol Nephrol 44:1813-1823

24. Siris ES, Harris ST, Rosen CJ, Barr CE, Arvesen JN, Abbott TA, Silverman S (2006) Adherence to bisphosphonate therapy and fracture rates in osteoporotic women: relationship to vertebral and nonvertebral fractures from 2 US claims databases. Mayo Clin Proc 81:1013-1022 25. Silverman SL (2010) Osteoporosis therapies: evidence from health-care databases and observational population studies. Calcif Tissue Int 87:375-384

26. Eiken P, Vestergaard P (2015) Treatment of osteoporosis after alendronate or risedronate. Osteoporos Int

27. Johnell O, Scheele WH, Lu Y, Reginster J-Y, Need AG, Seeman E (2002) Additive Effects of Raloxifene and Alendronate on Bone Density and Biochemical Markers of Bone Remodeling in Postmenopausal Women with Osteoporosis. Journal of Clinical Endocrinology \& Metabolism 87:985-992

28. Sambrook PN, Flahive J, Hooven FH, et al. (2011) Predicting fractures in an international cohort using risk factor algorithms without BMD. J Bone Miner Res 26:2770-2777 
Figure 1: Cohort Inclusions $(n=7435)$

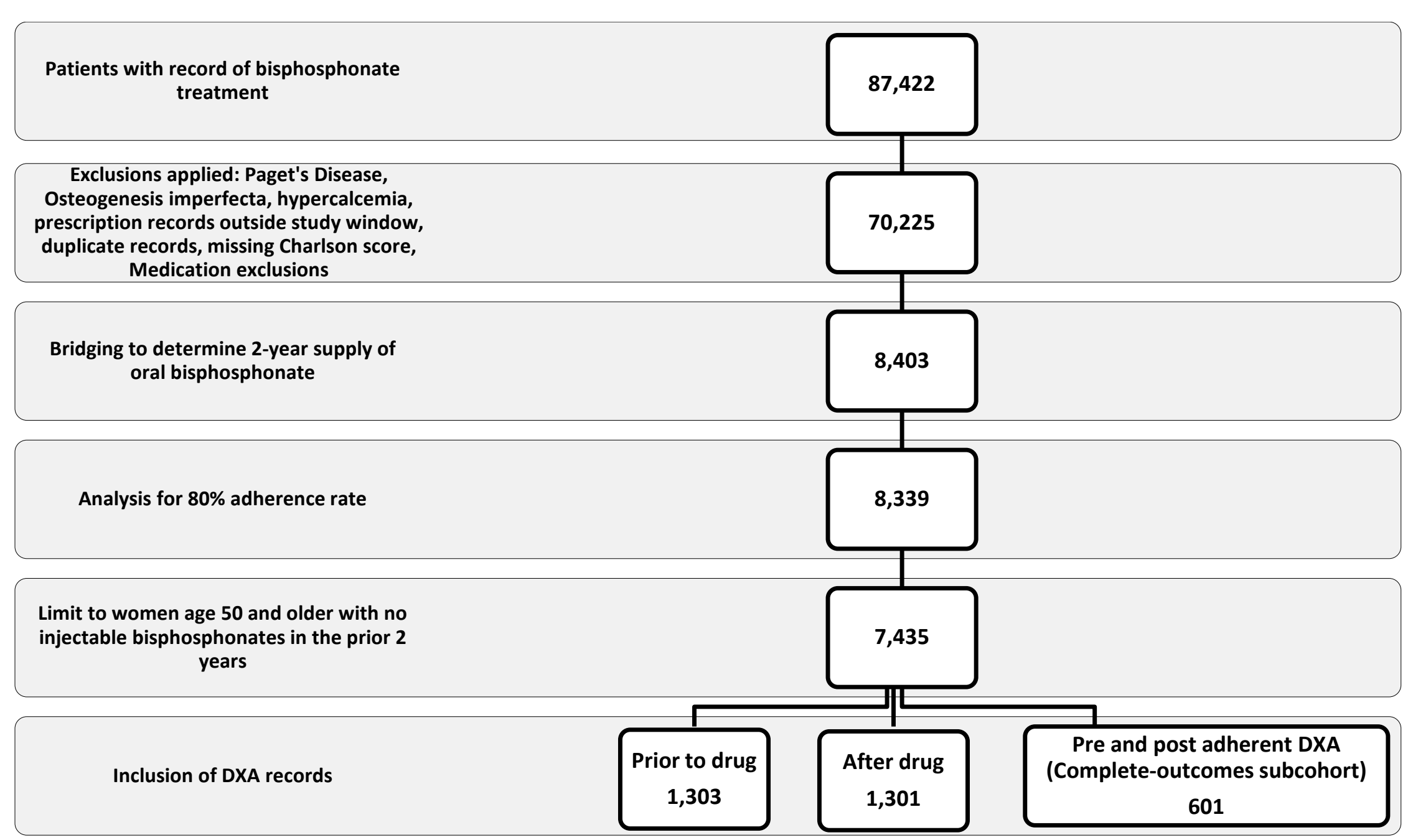


Table 1: Demographics, adherence and pre-index bone-related measures, and comorbidities of the cohort. Values are provided as mean (SD) or $\mathrm{N}(\%)$

\begin{tabular}{|c|c|c|c|}
\hline & & All $(n=7435)$ & $\begin{array}{l}\text { Complete-outcomes } \\
\text { Subcohort having } \\
\text { pre and post- } \\
\text { adherent DXA } \\
(\mathrm{n}=601)\end{array}$ \\
\hline Demographics & & & \\
\hline Age at index & & $68(10)$ & $66(9)$ \\
\hline Race & Black & $493(7 \%)$ & $46(8 \%)$ \\
\hline & Hispanic & $23(<1 \%)$ & $5(1 \%)$ \\
\hline & Missing & $1228(17 \%)$ & $29(5 \%)$ \\
\hline & White & $5691(77 \%)$ & $521(87 \%)$ \\
\hline Adherence Measures & & & \\
\hline Proportion of days covered & & $0.96(0.04)$ & $0.96(0.04)$ \\
\hline $\begin{array}{l}\text { Length of Bisphosphonate Adherent } \\
\text { Period (days) }\end{array}$ & & $1019(272)$ & $1053(289)$ \\
\hline Length of Bisphosphonate Adherent & $2-2.224$ & $1855(25 \%)$ & $104(17 \%)$ \\
\hline & $2.25-2.49$ & $1336(18 \%)$ & $103(17 \%)$ \\
\hline & $2.5-2.74$ & $1017(14 \%)$ & $91(15 \%)$ \\
\hline & $2.75-2.99$ & $984(13 \%)$ & $95(16 \%)$ \\
\hline & $3+$ & $2243(30 \%)$ & $208(35 \%)$ \\
\hline Pre-index Bone Measures & & & \\
\hline Fracture pre-index & & $680(9 \%)$ & $62(10 \%)$ \\
\hline Minimum T-score within 2 years pre-index & $\leq-2.5$ & $350(27 \%)$ & $152(25 \%)$ \\
\hline & $>-2.5$ & $953(73 \%)$ & $446(75 \%)$ \\
\hline & Missing & 6132 & \\
\hline Pre-index Osteoporosis Medications & & & \\
\hline Any osteoporosis drug & & $2249(30 \%)$ & $211(35 \%)$ \\
\hline Calcitonin & & $63(1 \%)$ & $6(1 \%)$ \\
\hline Teriparatide & & $33(<1 \%)$ & $4(1 \%)$ \\
\hline Any bisphosphonates & & $2215(30 \%)$ & $206(34 \%)$ \\
\hline Risedronate & & $692(9 \%)$ & $50(8 \%)$ \\
\hline Ibandronate & & $222(3 \%)$ & $23(4 \%)$ \\
\hline Alendronate & & $1441(19 \%)$ & $150(25 \%)$ \\
\hline Comorbidities & & & \\
\hline 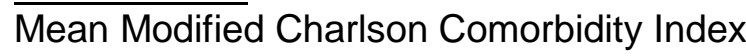 & $(S D)^{b}$ & $1.26(1.78)$ & $1.23(1.86)$ \\
\hline AIDS & & $6(<1 \%)$ & $1(<1 \%)$ \\
\hline Any Malignancy & & $1089(15 \%)$ & $100(17 \%)$ \\
\hline Chronic pulmonary diseases & & $1599(22 \%)$ & $125(21 \%)$ \\
\hline Inflammatory and other chronic joint conditi & & $2733(37 \%)$ & $233(39 \%)$ \\
\hline Neurologic conditions & & $1805(24 \%)$ & $133(22 \%)$ \\
\hline Cardiovascular conditions (other than cereb & rovascular) & $4272(57 \%)$ & $348(58 \%)$ \\
\hline Diabetes & & $1035(14 \%)$ & $67(11 \%)$ \\
\hline Hyperparathyroidism & & $67(1 \%)$ & $6(1 \%)$ \\
\hline Vitamin D deficiency & & $401(5 \%)$ & $40(7 \%)$ \\
\hline Renal disease & & $369(5 \%)$ & $24(4 \%)$ \\
\hline Gastrointestinal disorders & & $1895(25 \%)$ & $159(26 \%)$ \\
\hline
\end{tabular}


a Three subjects in the complete outcomes cohort were missing pre-index T-scores, but BMD value (without listing T-score) was available from the existing reports.

${ }^{b}$ The Charlson Comorbidity Index is a scale generated from ICD9 codes, and higher index values indicate greater comorbidities.

Table 2: Medications used during the adherent period

\begin{tabular}{|lcc|}
\hline & All $(\mathrm{n}=7435)$ & $\begin{array}{c}\text { Complete-outcomes } \\
\text { subcohort having pre and } \\
\text { post-adherent DXA } \\
(\mathrm{n}=601)\end{array}$ \\
\hline${\text { Bisphosphonates }{ }^{\text {a }}}^{\text {Risedronate }}$ & $\mathrm{N}(\%)$ & $\mathrm{N}(\%)$ \\
lbandronate sodium & $2011(27 \%)$ & $131(22 \%)$ \\
Alendronate & $774(10 \%)$ & $72(12 \%)$ \\
Other Medications & $5254(71 \%)$ & $454(76 \%)$ \\
Calcitonin-salmon & & $7(1 \%)$ \\
Estrogens & $66(1 \%)$ & $71(7 \%)$ \\
Tamoxifen & $718(10 \%)$ & $6(1 \%)$ \\
Aromatase inhibitor & $53(1 \%)$ & $25(4 \%)$ \\
Raloxifene & $222(3 \%)$ & $28(5 \%)$ \\
Thiazide diuretics & $295(4 \%)$ & $95(16 \%)$ \\
Glucocorticoids & $1273(17 \%)$ & $207(34 \%)$ \\
Proton pump inhibitors & $2602(35 \%)$ & $119(20 \%)$ \\
SSRls/SNRIs & $1662(22 \%)$ & $143(24 \%)$ \\
Anticonvulsants & $1723(23 \%)$ & $97(16 \%)$ \\
Statins & $1138(15 \%)$ & $261(43 \%)$ \\
Antidiabetics & $3283(44 \%)$ & $19(3 \%)$ \\
Coumadin/anticoagulants & $191(3 \%)$ & $27(4 \%)$ \\
Cyclosporin cytotoxic agents & $399(5 \%)$ & $7(1 \%)$ \\
\hline
\end{tabular}

${ }^{a}$ Some subjects changed oral bisphosphonate during the adherent period.

${ }^{b} \mathrm{p}<0.01$

${ }^{c} p<0.05$ 
Table 3: Outcomes: Fracture, low T-score $\leq-2.5$, change in BMD (from corresponding pre- to post-index periods), and composite outcomes

\begin{tabular}{|c|c|}
\hline Full cohort $(n=7435)$ & $\mathrm{N}(\%)$ \\
\hline Fracture (7-36 months post-index) & $499(7 \%)$ \\
\hline $\begin{array}{l}\text { Low T-score (minimum T-score } \leq-2.5) \text { BMD from 13-36 } \\
\text { months post-index }(n=1301)\end{array}$ & 264 (20\%). \\
\hline \multicolumn{2}{|l|}{$\begin{array}{l}\text { Complete-outcomes subcohort } \\
\text { having pre and post-adherent DXA }(n=601)\end{array}$} \\
\hline Fracture (7-36 months post-index) & $38(6 \%)$ \\
\hline $\begin{array}{l}\text { Low T-score (minimum T-score } \leq-2.5 \text { ) from } 13-36 \text { months } \\
\text { post-index }\end{array}$ & $131(22 \%)$ \\
\hline \multicolumn{2}{|l|}{$\begin{array}{l}\text { BMD change }^{*} \\
\text { Femur }\end{array}$} \\
\hline $\begin{array}{l}\text { Mean (SD) of overall \% change } \\
\text { Increase } \geq 5 \% \\
\text { Remained unchanged (within } \pm 5 \% \text { ) } \\
\text { Decrease } \geq 5 \%\end{array}$ & $\begin{array}{l}0.71(5.85) \\
51(22 \%) \\
148(63 \%) \\
37(16 \%)\end{array}$ \\
\hline \multicolumn{2}{|l|}{ Total hip $(n=553)$} \\
\hline Mean (SD) of overall \% change & $1.28(5.37)$ \\
\hline Increase $\geq 5 \%$ & $112(20 \%)$ \\
\hline Remained unchanged (within $\pm 5 \%$ ) & $393(71 \%)$ \\
\hline Decrease $\geq 5 \%$ & $48(9 \%)$ \\
\hline \multicolumn{2}{|l|}{ Spine $(n=506)$} \\
\hline Mean (SD) of overall \% change & $3.29(7.58)$ \\
\hline Increase $\geq 5 \%$ & $185(37 \%)$ \\
\hline Remained unchanged (within $\pm 5 \%$ ) & $283(56 \%)$ \\
\hline Decrease $\geq 5 \%$ & $38(8 \%)$ \\
\hline \multicolumn{2}{|l|}{ Worst BMD change at any site $(n=601)$} \\
\hline Increase $\geq 5 \%$ & $69(11 \%)$ \\
\hline Remained unchanged (within $\pm 5 \%$ ) & $434(72 \%)$ \\
\hline Decrease $\geq 5 \%$ & $98(16 \%)$ \\
\hline Mean of minimum \% change at any site, mean (SD) & $-0.62(5.55)$ \\
\hline $\begin{array}{l}\text { Composite outcome (one or more of the following: fracture, } \\
\text { minimum } T \text {-score } \leq-2.5 \text {, or BMD decrease } \geq 5 \% \text { ) }\end{array}$ & 207 (35\%) \\
\hline
\end{tabular}

${ }^{\star}$ Due to rounding, percent of patients in categories at a BMD site may not add up to exactly $100 \%$. Not every patient had data available for all 3 sites, so the numbers with DXA at each site varied. 
Table 4: Prediction of 7-36 month post-index fracture by each individual predictor for entire cohort of 7435 women with 499 fracture outcomes: univariate estimates of association

\begin{tabular}{|c|c|c|c|c|c|c|}
\hline & & Fracture & No Fracture & OR $(95 \% \mathrm{Cl})$ & $p$-value & \\
\hline & & $\mathrm{N}(\%)$ & $\mathrm{N}(\%)$ & & & \\
\hline Total $n=7435$ & & $499(6.7 \%)$ & $6936(93.3 \%)$ & & & \\
\hline Age at index & & $72.77(10.98)$ & $67.31(10.29)$ & $1.27(1.22,1.33)$ & $<0.0001$ & * \\
\hline Black race & $\begin{array}{l}\text { Yes } \\
\text { No }\end{array}$ & $\begin{array}{c}35(7 \%) \\
464(7 \%)\end{array}$ & $\begin{array}{c}458(93 \%) \\
6478(93 \%)\end{array}$ & $1.07(0.75,1.52)$ & 0.7217 & \\
\hline Fracture pre-index & Yes & $130(19 \%)$ & $550(81 \%)$ & $4.09(3.29,5.09)$ & $<0.0001$ & * \\
\hline & No & $369(5 \%)$ & $6386(95 \%)$ & & & \\
\hline $\begin{array}{l}\text { Minimum pre-index T-score of femoral neck, } \\
\text { hip spine } \leq-25\end{array}$ & Yes & $29(8 \%)$ & $321(92 \%)$ & $1.22(0.83,1.81)$ & 0.3162 & \\
\hline & $\begin{array}{l}\text { No } \\
\text { missing }\end{array}$ & $\begin{array}{c}48(5 \%) \\
422(7 \%)\end{array}$ & $\begin{array}{c}905(95 \%) \\
5710(93 \%)\end{array}$ & $0.72(0.53,0.98)$ & 0.0340 & * \\
\hline Co-morbidities & & & & & & \\
\hline 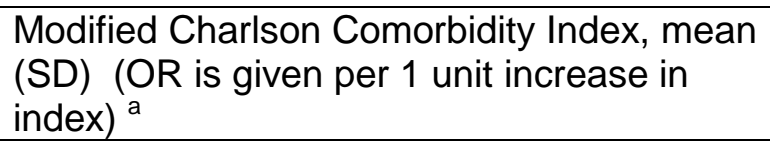 & & $2.36(2.35)$ & $1.18(1.70)$ & $1.29(1.24,1.34)$ & $<0.0001$ & * \\
\hline ( & $\begin{array}{l}\text { Yes } \\
\text { No }\end{array}$ & $\begin{array}{c}2(33 \%) \\
497(7 \%) \\
\end{array}$ & $\begin{array}{c}4(67 \%) \\
6932(93 \%) \\
\end{array}$ & $6.97(1.27,38.17)$ & 0.0251 & * \\
\hline Any Malignancy & $\begin{array}{l}\text { Yes } \\
\text { No }\end{array}$ & $\begin{array}{l}103(9 \%) \\
396(6 \%)\end{array}$ & $\begin{array}{c}986(91 \%) \\
5950(94 \%)\end{array}$ & $1.57(1.25,1.97)$ & 0.0001 & * \\
\hline Chronic pulmonary diseases & $\begin{array}{l}\text { Yes } \\
\text { No }\end{array}$ & $\begin{array}{c}163(10 \%) \\
336(6 \%)\end{array}$ & $\begin{array}{l}1436(90 \%) \\
5500(94 \%)\end{array}$ & $1.86(1.53,2.26)$ & $<0.0001$ & * \\
\hline $\begin{array}{l}\text { Inflammatory and other chronic joint } \\
\text { conditions }\end{array}$ & $\begin{array}{l}\text { Yes } \\
\text { No }\end{array}$ & $\begin{array}{c}289(11 \%) \\
210(4 \%)\end{array}$ & $\begin{array}{l}2444(89 \%) \\
4492(96 \%)\end{array}$ & $2.53(2.10,3.04)$ & $<0.0001$ & * \\
\hline Neurologic conditions & $\begin{array}{l}\text { Yes } \\
\text { No }\end{array}$ & $\begin{array}{c}229(13 \%) \\
270(5 \%)\end{array}$ & $\begin{array}{l}1576(87 \%) \\
5360(95 \%)\end{array}$ & $2.89(2.40,3.47)$ & $<0.0001$ & * \\
\hline $\begin{array}{l}\text { Cardiovascular conditions (other than } \\
\text { cerebrovascular) }\end{array}$ & $\begin{array}{l}\text { Yes } \\
\text { No }\end{array}$ & $\begin{array}{l}383(9 \%) \\
116(4 \%) \\
\end{array}$ & $\begin{array}{l}3889(91 \%) \\
3047(96 \%) \\
\end{array}$ & $2.59(2.09,3.20)$ & $<0.0001$ & * \\
\hline Diabetes & $\begin{array}{l}\text { Yes } \\
\text { No }\end{array}$ & $\begin{array}{c}119(11 \%) \\
380(6 \%)\end{array}$ & $\begin{array}{c}916(89 \%) \\
6020(94 \%)\end{array}$ & $2.06(1.66,2.56)$ & $<0.0001$ & * \\
\hline Hyperparathyroidism & Yes & $5(7 \%)$ & $62(93 \%)$ & $1.12(0.45,2.80)$ & 0.8051 & \\
\hline
\end{tabular}




\begin{tabular}{|c|c|c|c|c|c|c|}
\hline & No & $494(7 \%)$ & $6874(93 \%)$ & & & \\
\hline Vitamin D deficiency & $\begin{array}{l}\text { Yes } \\
\text { No }\end{array}$ & $\begin{array}{c}31(8 \%) \\
468(7 \%)\end{array}$ & $\begin{array}{c}370(92 \%) \\
6566(93 \%)\end{array}$ & $1.18(0.81,1.72)$ & 0.4021 & \\
\hline Renal disease & $\begin{array}{l}\text { Yes } \\
\text { No }\end{array}$ & $\begin{array}{l}69(19 \%) \\
430(6 \%)\end{array}$ & $\begin{array}{c}300(81 \%) \\
6636(94 \%)\end{array}$ & $3.55(2.68,4.69)$ & $<0.0001$ & * \\
\hline Gastrointestinal disorders & $\begin{array}{l}\text { Yes } \\
\text { No }\end{array}$ & $\begin{array}{c}160(10 \%) \\
339(6 \%)\end{array}$ & $\begin{array}{l}1387(90 \%) \\
5549(94 \%)\end{array}$ & $1.89(1.55,2.30)$ & $<0.0001$ & * \\
\hline \multicolumn{6}{|l|}{ Pre-index treatments } & \\
\hline Risedronate pre-index & $\begin{array}{l}\text { Yes } \\
\text { No }\end{array}$ & $\begin{array}{c}51(7 \%) \\
448(7 \%)\end{array}$ & $\begin{array}{c}641(93 \%) \\
6295(93 \%)\end{array}$ & $1.12(0.83,1.51)$ & 0.4675 & \\
\hline Ibandronate sodium pre-index & $\begin{array}{l}\text { Yes } \\
\text { No }\end{array}$ & $\begin{array}{c}17(8 \%) \\
482(7 \%)\end{array}$ & $\begin{array}{c}205(92 \%) \\
6731(93 \%)\end{array}$ & $1.16(0.70,1.92)$ & 0.5676 & \\
\hline Alendronate pre-index & $\begin{array}{l}\text { Yes } \\
\text { No }\end{array}$ & $\begin{array}{c}90(6 \%) \\
409(7 \%)\end{array}$ & $\begin{array}{l}1351(94 \%) \\
5585(93 \%)\end{array}$ & $0.91(0.72,1.15)$ & 0.4314 & \\
\hline Any bisphosphonate treatment pre-index & $\begin{array}{l}\text { Yes } \\
\text { No }\end{array}$ & $\begin{array}{l}149(7 \%) \\
350(7 \%)\end{array}$ & $\begin{array}{l}2066(93 \%) \\
4870(93 \%)\end{array}$ & $1.00(0.82,1.22)$ & 0.9725 & \\
\hline Calcitonin pre-index & $\begin{array}{l}\text { Yes } \\
\text { No }\end{array}$ & $\begin{array}{l}12(19 \%) \\
487(7 \%)\end{array}$ & $\begin{array}{c}51(81 \%) \\
6885(93 \%)\end{array}$ & $3.33(1.76,6.28)$ & 0.0002 & * \\
\hline Teriparatide pre-index & $\begin{array}{l}\text { Yes } \\
\text { No }\end{array}$ & $\begin{array}{c}7(21 \%) \\
492(7 \%) \\
\end{array}$ & $\begin{array}{c}26(79 \%) \\
6910(93 \%) \\
\end{array}$ & $3.78(1.63,8.76)$ & 0.0019 & * \\
\hline Any osteoporosis treatment pre-index & $\begin{array}{l}\text { Yes } \\
\text { No }\end{array}$ & $\begin{array}{l}152(7 \%) \\
347(7 \%)\end{array}$ & $\begin{array}{l}2097(93 \%) \\
4839(93 \%)\end{array}$ & $1.01(0.83,1.23)$ & 0.9148 & \\
\hline \multicolumn{6}{|l|}{ Drugs during adherent period. } & \\
\hline Risedronate during adherent period & $\begin{array}{l}\text { Yes } \\
\text { No }\end{array}$ & $\begin{array}{l}135(7 \%) \\
364(7 \%) \\
\end{array}$ & $\begin{array}{l}1876(93 \%) \\
5060(93 \%) \\
\end{array}$ & $1.00(0.82,1.23)$ & 1.0000 & \\
\hline Ibandronate sodium during adherent period & $\begin{array}{l}\text { Yes } \\
\text { No }\end{array}$ & $\begin{array}{c}51(7 \%) \\
448(7 \%)\end{array}$ & $\begin{array}{c}723(93 \%) \\
6213(93 \%)\end{array}$ & $0.98(0.73,1.32)$ & 0.8866 & \\
\hline Alendronate during adherent period & $\begin{array}{l}\text { Yes } \\
\text { No }\end{array}$ & $\begin{array}{l}368(7 \%) \\
131(6 \%) \\
\end{array}$ & $\begin{array}{l}4886(93 \%) \\
2050(94 \%) \\
\end{array}$ & $1.18(0.96,1.45)$ & 0.1179 & \\
\hline $\begin{array}{l}\text { Additional concomitant medications during } \\
\text { bisphosphonate adherent period }\end{array}$ & & & & & & \\
\hline Calcitonin during adherent period & $\begin{array}{l}\text { Yes } \\
\text { No }\end{array}$ & $\begin{array}{l}10(15 \%) \\
489(7 \%)\end{array}$ & $\begin{array}{c}56(85 \%) \\
6880(93 \%)\end{array}$ & $2.51(1.28,4.96)$ & 0.0078 & * \\
\hline Glucocorticoids during adherent period & Yes & $178(7 \%)$ & $2424(93 \%)$ & $1.03(0.85,1.25)$ & 0.7443 & \\
\hline
\end{tabular}




\begin{tabular}{|c|c|c|c|c|c|}
\hline & No & $321(7 \%)$ & $4511(93 \%)$ & & \\
\hline Tamoxifen during adherent period & $\begin{array}{l}\text { Yes } \\
\text { No }\end{array}$ & $\begin{array}{c}7(13 \%) \\
492(7 \%)\end{array}$ & $\begin{array}{c}46(87 \%) \\
6890(93 \%)\end{array}$ & $2.13(0.96,4.75)$ & 0.0638 \\
\hline Aromatase inhibitor during adherent period & $\begin{array}{l}\text { Yes } \\
\text { No }\end{array}$ & $\begin{array}{c}18(8 \%) \\
481(7 \%)\end{array}$ & $\begin{array}{c}204(92 \%) \\
6732(93 \%)\end{array}$ & $1.24(0.76,2.02)$ & 0.3990 \\
\hline Raloxifene during adherent period & $\begin{array}{l}\text { Yes } \\
\text { No }\end{array}$ & $\begin{array}{c}22(7 \%) \\
477(7 \%)\end{array}$ & $\begin{array}{c}273(93 \%) \\
6663(93 \%)\end{array}$ & $1.13(0.72,1.76)$ & 0.6014 \\
\hline Estrogens during adherent period & $\begin{array}{l}\text { Yes } \\
\text { No }\end{array}$ & $\begin{array}{c}52(7 \%) \\
447(7 \%)\end{array}$ & $\begin{array}{c}666(93 \%) \\
6269(93 \%)\end{array}$ & $1.10(0.81,1.48)$ & 0.5506 \\
\hline
\end{tabular}

${ }^{a}$ The Charlson Comorbidity Index is a scale generated from ICD9 codes, and higher index values indicate greater comorbidities.

* Marks significant $p$ values. 
Table 5: Multivariable prediction of outcomes: Fractures in entire cohort and composite outcome in the complete-outcomes subcohort

\begin{tabular}{|c|c|c|c|}
\hline Outcome & Predictor & OR $(95 \% \mathrm{Cl})$ & p-value \\
\hline \multicolumn{4}{|l|}{ Entire cohort $(n=7435)$} \\
\hline \multirow{9}{*}{ Fractures (1 or more) } & Age at index & $1.03(1.02,1.04)$ & $<0.0001$ \\
\hline & Charlson Comorbidity Index ${ }^{a}$ & $1.14(1.09,1.20)$ & $<0.0001$ \\
\hline & Inflammatory and other chronic joint conditions & $1.64(1.34,2.00)$ & $<0.0001$ \\
\hline & Neurologic conditions & $1.55(1.25,1.91)$ & 0.0001 \\
\hline & Cardiovascular conditions (other than & & \\
\hline & cerebrovascular) & $1.33(1.04,1.68)$ & 0.0206 \\
\hline & Alendronate pre-index & $0.69(0.54,0.89)$ & 0.0037 \\
\hline & Calcitonin pre-index & $2.10(1.07,4.12)$ & 0.0318 \\
\hline & Fracture pre-index & $2.59(2.05,3.28)$ & $<0.0001$ \\
\hline \multicolumn{4}{|c|}{$\begin{array}{l}\text { Complete-outcomes subcohort } \\
\text { having pre and post-adherent DXA } \\
(n=601)\end{array}$} \\
\hline \multirow{4}{*}{$\begin{array}{l}\text { Composite outcome } \\
\text { (Fractures, T-score } \leq-2.5 \text {, BMD } \\
\text { decrease } \geq 5 \% \text { ) }\end{array}$} & Age at index & $1.05(1.03,1.08)$ & $<0.0001$ \\
\hline & Black race & $0.37(0.17,0.79)$ & 0.0105 \\
\hline & Hyperparathyroidism & $7.01(1.18,41.7)$ & 0.0322 \\
\hline & Estrogens during adherent period & $2.41(1.23,4.71)$ & 0.0100 \\
\hline
\end{tabular}

a The Charlson Comorbidity Index is a scale generated from ICD9 codes, and higher index values indicate greater comorbidities. 
Supplemental Table 1: ICD-9 codes used in the study

\begin{tabular}{|c|c|}
\hline \multicolumn{2}{|l|}{ Osteoporosis and fracture codes } \\
\hline Osteopenia and Osteoporosis & 2317, 3846, 733.0-733.03, 733.09, 733.9, 733.90 \\
\hline $\begin{array}{l}\text { Fracture codes used for outcome } \\
\text { events }\end{array}$ & $\begin{array}{l}\text { 733.1-733.16, 733.19, 805-808, 812-813, 818-821, } \\
\text { 823, 827-828 }\end{array}$ \\
\hline \multicolumn{2}{|l|}{ Exclusion criteria } \\
\hline Hypercalcemia & 275.42 \\
\hline Pagets Disease of Bone & 731.0 \\
\hline Osteogenesis Imperfecta & 756.51 \\
\hline \multicolumn{2}{|c|}{ Charlson comorbidity score components } \\
\hline Any Malignancy & $140-172,174-195,200-205$ \\
\hline Chronic Pulmonary Disease & $490-496,500-505,506.4$ \\
\hline Diabetes (and Complications) & 250 \\
\hline Hemiplegia or Paraplegia & $342,344.1$ \\
\hline Mild Liver Disease & $571.2,571.4-571.6$ \\
\hline Myocardial Infarction & 410 \\
\hline Peptic Ulcer Disease & $531-534$ \\
\hline Renal Disease & $582-583,585-586,588$ \\
\hline Rheumatologic Disease & $710,714,725$ \\
\hline \multicolumn{2}{|l|}{ Additional comorbidities included } \\
\hline Celiac Disease & 579 \\
\hline Chronic Inflammatory Bowel & $555-556$ \\
\hline Chronic Inflammatory Joint & $714-715$ \\
\hline Depression & 311 \\
\hline Gastrointestinal \& Urination & 788 \\
\hline Glucocorticoid therapy & 255.41 \\
\hline Hyperparathyroidism & 252 \\
\hline Hypertension & $401-405$ \\
\hline Neurologic Conditions & $326,330-336,340-345,355-359$ \\
\hline Renal Impairment & $585-585.6,585.9$ \\
\hline Vitamin D Deficiency & $268,268.9$ \\
\hline
\end{tabular}


Supplemental Table 2; Secondary analysis using 2 or more fractures as an outcome.

\begin{tabular}{|llrr|}
\hline Outcome & Predictor & OR (95\% Cl) & p-value \\
\hline Entire cohort (n= 7435) & & & \\
Fractures (2 or more) & Age at index & $1.04(1.03,1.06)$ & $<0.0001$ \\
& Charlson Comorbidity Index & $1.16(1.09,1.24)$ & $<.0001$ \\
& Black race & $0.43(0.20,0.93)$ & 0.0316 \\
& Inflammatory and other chronic joint & $2.49(1.78,3.49)$ & $<0.0001$ \\
& conditions & & 0.0006 \\
& Neurologic conditions & $1.80(1.29,2.53)$ & 0.0164 \\
\hline Complete-outcomes subcohort & Alendronate pre-index & $0.59(0.39,0.91)$ & \\
having pre and post-adherent DXA & & & \\
(n=601) & & & $<0.0001$ \\
Composite outcome & Age at index & $1.05(1.03,1.08)$ & 0.0272 \\
$(2$ or more fractures, & Black race & $0.40(0.18,0.90)$ & 0.0374 \\
T-score $\leq-2.5$, or & Diabetes & $0.51(0.27,0.96)$ & 0.0128 \\
BMD decrease $\geq 5 \%)$ & Hyperparathyroidism & $9.58(1.62,56.74)$ & 0.014 \\
& Risedronate during adherent period & $1.74(1.15,2.66)$ & 0.0096 \\
& Estrogens during adherent period & $2.20(1.12,4.33)$ & 0.0227 \\
\hline
\end{tabular}

